\title{
ACCURATE AND EFFICIENT COMPUTATIONS FOR THE GREEKS OF EUROPEAN MULTI-ASSET OPTIONS
}

\author{
SEUNGGYU LEE ${ }^{1}$, YIBAO LI $^{2}$, YONGHO CHOI $^{1}$, HYOUNGSEOK HWANG $^{3}$, AND JUNSEOK KIM ${ }^{1 \dagger}$ \\ ${ }^{1}$ Department of Mathematics, Korea University, Seoul 136-713, Korea \\ E-mail address: cfdkimekorea.ac.kr \\ 2 Department of Computational Science and Engineering, Yonsei University, Seoul 120 - \\ 749, KOREA \\ ${ }^{3}$ Department of Financial Engineering, Korea University, Seoul 136-071, Korea
}

\begin{abstract}
This paper presents accurate and efficient numerical methods for calculating the sensitivities of two-asset European options, the Greeks. The Greeks are important financial instruments in management of economic value at risk due to changing market conditions. The option pricing model is based on the Black-Scholes partial differential equation. The model is discretized by using a finite difference method and resulting discrete equations are solved by means of an operator splitting method. For Delta, Gamma, and Theta, we investigate the effect of high-order discretizations. For Rho and Vega, we develop an accurate and robust automatic algorithm for finding an optimal value. A cash-or-nothing option is taken to demonstrate the performance of the proposed algorithm for calculating the Greeks. The results show that the new treatment gives automatic and robust calculations for the Greeks.
\end{abstract}

\section{INTRODUCTION}

The Greeks, playing key roles in risk management, are the quantities representing the sensitivity of the price of derivatives. The Greeks are also termed the risk sensitivities [1], risk measures [2] or hedge parameters [3]. The Greeks are important in the hedging of an option position [4]. Therefore, it is essential to accurately and robustly estimate the Greeks. Although the Monte Carlo simulation has been widely used to calculate the option values [5, 6], it is very costly to compute the Greeks accurately and stably. Hence, up to options with two-underlying assets, it is common practice to use finite difference methods in evaluation the option price and its Greeks. However, there is no guideline in choosing the increment step sizes for an optimal calculation of the Greeks in authors' knowledge.

In this paper, we present accurate and efficient numerical methods for calculating the Greeks of the sensitivities of two-asset European options and optimal and robust guideline in choosing the increment step sizes. The model is discretized by using a finite difference method and

Received by the editors February 6 2014; Accepted February 25 2014; Published online March 1, 2014.

2000 Mathematics Subject Classification. 93B05.

Key words and phrases. Greek, two-asset option, finite difference method, cash-or-nothing.

${ }^{\dagger}$ Corresponding author. 
resulting discrete equations are solved by means of an operator splitting (OS) method. For Delta, Gamma, and Theta, we investigate the effect of high-order discretizations. For Rho and Vega, we develop an accurate and robust algorithm for finding an optimal value.

The rest of the paper is organized as follows. Section 2 represents the Black-Scholes (BS) model [7] with two underlying assets. It contains the finite difference discretization for the BS partial differential equation and a numerical solution algorithm using the operator splitting method. In Section 3, we present and compare the numerically calculated option Greeks with the closed-form analytic solutions of cash-or-nothing option. Finally, conclusions are given in Section 4.

\section{THE BLACK-SCHOLES MODEL AND ITS NUMERICAL SOLUTION}

We focus on the two-dimensional BS equation

$$
\begin{aligned}
\frac{\partial u(x, y, \tau)}{\partial \tau}= & \frac{1}{2} \sigma_{1}^{2} x^{2} \frac{\partial^{2} u(x, y, \tau)}{\partial x^{2}}+\rho_{x y} \sigma_{1} \sigma_{2} x y \frac{\partial^{2} u(x, y, \tau)}{\partial x \partial y}+\frac{1}{2} \sigma_{2}^{2} y^{2} \frac{\partial^{2} u(x, y, \tau)}{\partial y^{2}} \\
& +r x \frac{\partial u(x, y, \tau)}{\partial x}+r y \frac{\partial u(x, y, \tau)}{\partial y}-r u(x, y, \tau), \\
u(x, y, \tau=0)= & \Phi(x, y),
\end{aligned}
$$

where $\tau=T-t$ and $T$ is the expiration time. $x$ and $y$ are two underlying asset prices. $\sigma_{1}$ and $\sigma_{2}$ are volatilities. $\rho$ is the correlation value. $r$ is the risk-free interest rate. Next, we discretize Eq. (2.1) on a computational domain $\Omega=(0, L) \times(0, M)$ with a uniform space step $h=L / N_{x}=M / N_{y}$ and a time step $\Delta \tau=T / N_{\tau}$, where $N_{x}, N_{y}$, and $N_{\tau}$ are the numbers of grid points in the $x-, y$-, and $\tau$-directions, respectively. And then, let $u_{i j}^{n} \equiv u\left(x_{i}, y_{j}, \tau^{n}\right)=$ $u((i-0.5) h,(j-0.5) h, n \Delta \tau)$, where $i=1, \ldots, N_{x}, j=1, \ldots, N_{y}$, and $n=0, \ldots, N_{\tau}$. Now, we apply an OS method to numerically solve the BS equation. The basic idea of OS method $[8,9]$ is to divide each time step into fractional time steps with simpler operators:

$$
\frac{v_{i j}^{n+1}-v_{i j}^{n}}{\Delta \tau}=\mathcal{L}_{B S}^{x}\left(v_{i j}^{n+\frac{1}{2}}\right)+\mathcal{L}_{B S}^{y}\left(v_{i j}^{n+1}\right),
$$

where

$$
\begin{aligned}
\mathcal{L}_{B S}^{x}\left(v_{i j}^{n+\frac{1}{2}}\right)= & \frac{\left(\sigma_{1} x_{i}\right)^{2}}{2} \frac{v_{i-1, j}^{n+\frac{1}{2}}-2 v_{i j}^{n+\frac{1}{2}}+v_{i+1, j}^{n+\frac{1}{2}}}{h^{2}}+r x_{i} \frac{v_{i+1, j}^{n+\frac{1}{2}}-v_{i-1, j}^{n+\frac{1}{2}}}{2 h}-\frac{1}{2} r v_{i j}^{n+\frac{1}{2}} \\
& +\frac{1}{2} \sigma_{1} \sigma_{2} \rho_{x y} x_{i} y_{j} \frac{v_{i+1, j+1}^{n}+v_{i-1, j-1}^{n}-v_{i+1, j-1}^{n}-v_{i-1, j+1}^{n}}{4 h^{2}}, \\
\mathcal{L}_{B S}^{y}\left(v_{i j}^{n+1}\right)= & \frac{\left(\sigma_{2} y_{j}\right)^{2}}{2} \frac{v_{i, j-1}^{n+1}-2 v_{i j}^{n+1}+v_{i, j+1}^{n+1}}{h^{2}}+r y_{j} \frac{v_{i, j+1}^{n+1}-v_{i, j-1}^{n+1}}{2 h}-\frac{1}{2} r v_{i j}^{n+1} \\
& +\frac{1}{2} \sigma_{1} \sigma_{2} \rho_{x y} x_{i} y_{j} \frac{v_{i+1, j+1}^{n+\frac{1}{2}}+v_{i-1, j-1}^{n+\frac{1}{2}}-v_{i+1, j-1}^{n+\frac{1}{2}}-v_{i-1, j+1}^{n+\frac{1}{2}}}{4 h^{2}} .
\end{aligned}
$$


Next, we solve the following two equations:

$$
\begin{gathered}
\frac{v_{i j}^{n+\frac{1}{2}}-v_{i j}^{n}}{\Delta \tau}=\mathcal{L}_{B S}^{x} v_{i j}^{n+\frac{1}{2}}, \\
\frac{v_{i j}^{n+1}-v_{i j}^{n+\frac{1}{2}}}{\Delta \tau}=\mathcal{L}_{B S}^{y} v_{i j}^{n+1}
\end{gathered}
$$

with the following linear boundary conditions:

$$
\begin{aligned}
& v_{0 j}^{n}=2 v_{1 j}^{n}-v_{2 j}^{n}, v_{N_{x}+1, j}^{n}=2 v_{N_{x}, j}^{n}-v_{N_{x}-1, j}^{n} \text { for } j=1, \cdots, N_{y}, \\
& v_{i 0}^{n}=2 v_{i 1}^{n}-v_{i 2}^{n}, v_{i, N_{y}+1}^{n}=2 v_{i, N_{y}}^{n}-v_{i, N_{y}-1}^{n} \text { for } i=1, \cdots, N_{x} .
\end{aligned}
$$

For more details, see a reference [10].

\section{NUMERICAL EXPERIMENTS}

In this section, we consider a cash-or-nothing option with two underlying assets in order to calculate values of the option and the Greeks. We perform numerical tests with two strike prices $K_{1}=K_{2}=100$ and Cash $K=10$ on a computational domain $\Omega=[0,300] \times[0,300]$ (see Fig. 1(a) for the initial configuration). Parameters are defined as follows: the risk-free interest rate $r=0.03$, volatilities $\sigma_{1}=\sigma_{2}=0.3$, and correlation $\rho_{x y}=0.5$. Unless otherwise stated, we take the spatial step size $h=1$, temporal step size $\Delta \tau=1 / 365$, and $T=0.5$ is the final time.

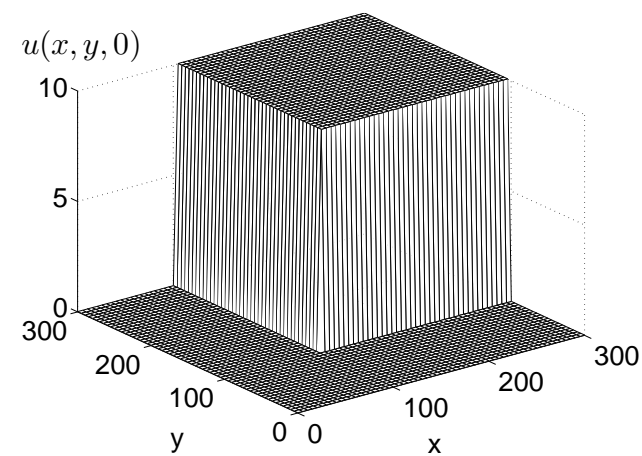

(a)

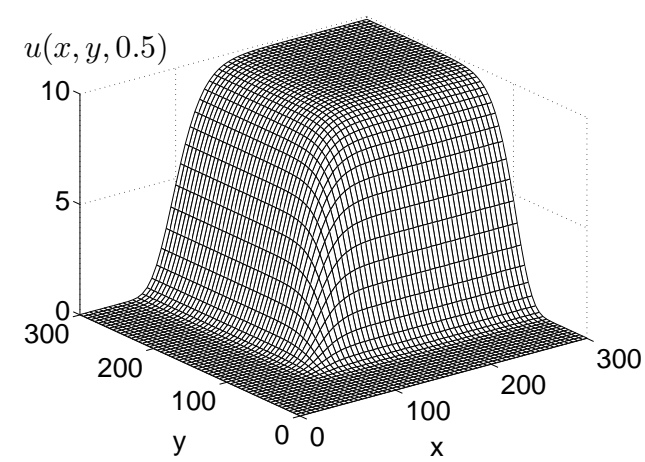

(b)

FIGURE 1. Cash-or-nothing option: (a) Initial profile and (b) numerical result at time $T=0.5$.

3.1. Convergence test. In this section, we perform a convergence test in order to verify accuracy of OS method which is used in this paper. Note that $u_{i j}$ and $v_{i j}$ be the values from 
the exact and numerical solutions at $\left(x_{i}, y_{j}\right)$, respectively, and we define the root mean square error (RMSE) as

$$
\mathrm{RMSE}=\sqrt{\frac{1}{N} \sum_{\left(x_{i}, y_{j}\right) \in \Omega_{0}}\left|u_{i j}-v_{i j}\right|^{2}}
$$

where $N$ is the number of grid points on $\Omega_{0}=\left[0.9 K_{1}, 1.1 K_{1}\right] \times\left[0.9 K_{2}, 1.1 K_{2}\right]$ (gray region in Fig. 2).

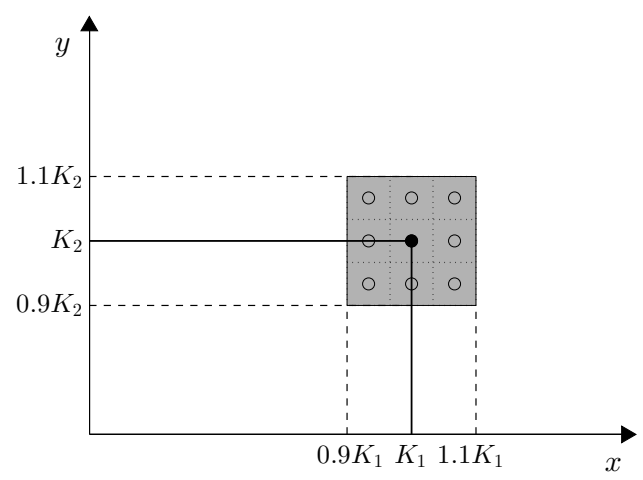

FIGURE 2. Schematic representation of $\Omega_{0}$ (gray region) on which RMSE is evaluated.

Table 1 shows the RMSE and the convergence rates. We perform this test with a fixed time step size $\Delta \tau=2.5 \times 10^{-5}$ up to the maturity $T=0.5$ (see Fig. 1(b) for the numerical solution). The test result shows that this method has the second order accuracy in space as shown in Table 1.

TABLE 1. RMSE and convergence rates with various mesh grids when $\Delta \tau=$ $2.5 \times 10^{-5}$.

\begin{tabular}{cccccc}
\hline Grid & $75 \times 75$ & & $150 \times 150$ & $300 \times 300$ & $600 \times 600$ \\
\hline $\begin{array}{c}\text { RMSE } \\
\text { Rate }\end{array}$ & 0.004959 & 0.001236 & 0.000310 & 0.000081 \\
\hline
\end{tabular}

To show the convergence rate for the temporal discretization, we fix a space step size as $h=0.125$ and choose a set of decreasing time steps $\Delta \tau=1.25 \mathrm{e}-2,6.25 \mathrm{e}-3,3.125 \mathrm{e}-3$ and 1.563e-3. Numerical solutions are computed up to time $T=0.5$. The RMSE and rates of convergence are given in Table 2. As expected from the discretization, the first-order accuracy with respect to time is observed. 
TABLE 2. RMSE and convergence rates with various mesh grids when $h=0.125$.

\begin{tabular}{cccccc}
\hline$\Delta \tau$ & 0.012500 & 0.006250 & 0.003125 & 0.001563 \\
\hline $\begin{array}{c}\text { RMSE } \\
\text { Rate }\end{array}$ & 0.015785 & 0.007834 & 0.003902 & 0.001947 \\
\hline
\end{tabular}

3.2. High order finite difference method for evaluating the Greeks. As a first test, we study high order finite difference schemes for evaluating the Greeks in order to improve the accuracy. To measure the accuracy, we use the relative error. The relative error is defined by $e_{\phi}=\left|\left(\phi^{e x}-\phi\right) / \phi^{e x}\right|$, where $\phi^{e x}$ is the exact solution and $\phi$ is the numerical solution for the Greeks. Note that the MATLAB codes for closed-form solutions of the Greeks for the cash-or-nothing with two asset options are given in Appendix.

3.2.1. Delta $(\Delta)$. Delta, $\Delta$, is defined as the rate of change of the option price with respect to changes in the underlying asset's price. By this definition, we can write Delta by using the various finite difference discretizations at $\left(x_{i}, y_{j}\right)$. For example,

$$
\begin{aligned}
\left(\Delta_{x}\right)_{i j}^{n} & :=\left(\frac{\partial u}{\partial x}\right)_{i j}^{n}=\frac{u_{i+1, j}^{n}-u_{i-1, j}^{n}}{2 h}+O\left(h^{2}\right) \\
& =\frac{u_{i-2, j}^{n}-8 u_{i-1, j}^{n}+8 u_{i+1, j}^{n}-u_{i+2, j}^{n}}{12 h}+O\left(h^{4}\right) \\
& =\frac{u_{i+3, j}^{n}-9 u_{i+2, j}^{n}+45 u_{i+1, j}^{n}-45 u_{i-1, j}^{n}+9 u_{i-2, j}^{n}-u_{i-3, j}^{n}}{60 h}+O\left(h^{6}\right) .
\end{aligned}
$$

Note that $u_{i j}^{n}$ is not a value of the numerical solution, but a value of the closed-form analytic solution. Table 3 shows the computational results from various $h$ values at $\left(x_{i}, y_{j}\right)=(100,100)$. Here the exact solution of $\Delta_{x}^{e x}$ is $9.106615123758730 \mathrm{e}-2$. Figure 3 shows a plot of $h$ versus the relative error of $\Delta_{x}$ corresponding to the results given in Table 3. As can be seen, the relative errors of the three mentioned methods are decreased as mesh refined. Compared with the second order difference discretizations, the fourth and sixth order ones significantly reduces the numerical errors. While the similar results, which are obtained by the fourth and sixth order ones, suggest that we can well calculate the Delta with fourth order discretization.

TABLE 3. Relative error of $\Delta_{x}$ with respect to $h$ and $\Delta_{x}^{e x}=$ $9.106615123758730 \mathrm{e}-2$.

\begin{tabular}{lcccccc}
\hline \multicolumn{1}{r}{$h$} & \multirow{2}{*}{0} & 0.5 & 0.25 & 0.125 & 0.0625 & 0.03125 \\
error & & & & & & \\
\hline 2nd order & $4.776 \mathrm{e}-4$ & $1.194 \mathrm{e}-4$ & $2.984 \mathrm{e}-5$ & $7.459 \mathrm{e}-6$ & $1.865 \mathrm{e}-6$ & $4.662 \mathrm{e}-7$ \\
4th order & $2.324 \mathrm{e}-4$ & $5.814 \mathrm{e}-5$ & $1.454 \mathrm{e}-5$ & $3.635 \mathrm{e}-6$ & $9.087 \mathrm{e}-7$ & $2.272 \mathrm{e}-7$ \\
6th order & $2.326 \mathrm{e}-4$ & $5.816 \mathrm{e}-5$ & $1.454 \mathrm{e}-5$ & $3.635 \mathrm{e}-6$ & $9.087 \mathrm{e}-7$ & $2.272 \mathrm{e}-7$ \\
\hline
\end{tabular}




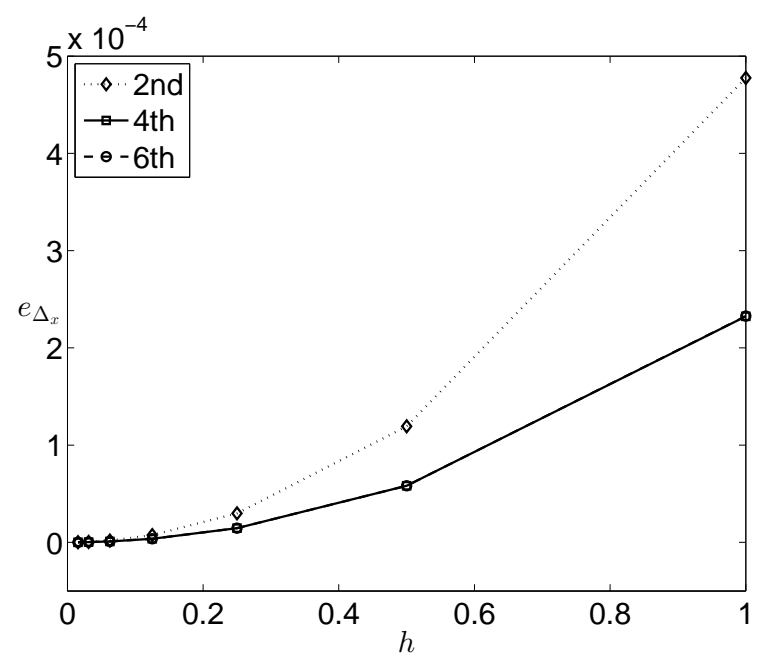

FIGURE 3. Relative error of $\Delta_{x}$ with 2nd, 4th, and 6th order schemes.

3.2.2. Gamma $(\Gamma)$. Gamma, $\Gamma$, is defined as the rate of change in the delta with respect to changes in the underlying asset's price. That is the second partial derivative of the portfolio value with respect to each asset price. The various order finite difference discretizations for Gamma at $\left(x_{i}, y_{j}\right)$ are given as

$$
\begin{aligned}
&\left(\Gamma_{x x}\right)_{i j}^{n}:=\left(\frac{\partial^{2} u}{\partial x^{2}}\right)_{i j}^{n}=\frac{u_{i+1, j}^{n}-2 u_{i j}^{n}+u_{i-1, j}^{n}}{h^{2}}+O\left(h^{2}\right) \\
&= \frac{-u_{i+2, j}^{n}+16 u_{i+1, j}^{n}-30 u_{i, j}^{n}+16 u_{i-1, j}^{n}-u_{i-2, j}^{n}}{12 h^{2}}+O\left(h^{4}\right) \\
&= \frac{1}{180 h^{2}}\left(2 u_{i+3, j}^{n}-27 u_{i+2, j}^{n}+270 u_{i+1, j}^{n}-490 u_{i j}^{n}+270 u_{i-1, j}^{n}\right. \\
&\left.-27 u_{i-2, j}^{n}+2 u_{i-3, j}^{n}\right)+O\left(h^{6}\right), \\
&\left(\Gamma_{x y}\right)_{i j}^{n}:=\left(\frac{\partial^{2} u}{\partial x \partial y}\right)_{i j}^{n}=\frac{u_{i+1, j+1}^{n}-u_{i-1, j+1}^{n}-u_{i+1, j-1}^{n}+u_{i-1, j-1}^{n}+O\left(h^{2}\right)}{4 h^{2}} \\
&= \frac{1}{48 h^{2}}\left(u_{i+2, j-2}^{n}+u_{i-2, j+2}^{n}-u_{i+2, j+2}^{n}-u_{i-2, j-2}^{n}+16 u_{i+1, j+1}^{n}\right. \\
&\left.\quad+16 u_{i-1, j-1}^{n}-16 u_{i+1, j-1}^{n}-16 u_{i-1, j+1}^{n}\right)+O\left(h^{4}\right) \\
&=\frac{1}{720 h^{2}}\left(2 u_{i+3, j+3}^{n}+2 u_{i-3, j-3}^{n}-2 u_{i+3, j-3}^{n}-2 u_{i-3, j+3}^{n}-27 u_{i+2, j+2}^{n}\right. \\
&-27 u_{i-2, j-2}^{n}+27 u_{i+2, j-2}^{n}+27 u_{i-2, j+2}^{n}+270 u_{i+1, j+1}^{n}+270 u_{i-1, j-1}^{n} \\
&\left.-270 u_{i+1, j-1}^{n}-270 u_{i-1, j+1}^{n}\right)+O\left(h^{6}\right) .
\end{aligned}
$$


With various $h$ and $\Gamma_{x x}^{e x}=-2.768767058441984 e-3, \Gamma_{x y}^{e x}=4.019764929590845 \mathrm{e}-3$, Table 4 shows the relative errors of $\Gamma_{x x}$ and $\Gamma_{x y}$. And Fig. 4 shows plots of the relative errors of $\Gamma_{x x}$ and $\Gamma_{x y}$. As the result of last section, both fourth and sixth order scheme much reduce the relative errors, but their results are also similar. These results suggest that fourth order discretization is a better choice to compute Gamma.

TABLE 4. Relative errors of $\Gamma_{x x}$ and $\Gamma_{x y}$ with various $h$ values and $\Gamma_{x x}^{e x}=$ $-2.768767058441984 e-3$ and $\Gamma_{x y}^{e x}=4.019764929590845 \mathrm{e}-3$.

\begin{tabular}{rr|cccccc}
\hline & $h$ & 1 & 0.5 & 0.25 & 0.125 & 0.0625 & 0.03125 \\
\hline & error & & & & & & \\
\hline$\Gamma_{x x}$ & 2nd order & $2.067 \mathrm{e}-3$ & $5.172 \mathrm{e}-4$ & $1.293 \mathrm{e}-4$ & $3.233 \mathrm{e}-5$ & $8.083 \mathrm{e}-6$ & $2.021 \mathrm{e}-6$ \\
& 4th order & $1.355 \mathrm{e}-3$ & $3.387 \mathrm{e}-4$ & $8.468 \mathrm{e}-5$ & $2.117 \mathrm{e}-5$ & $5.292 \mathrm{e}-6$ & $1.323 \mathrm{e}-6$ \\
& 6th order & $1.354 \mathrm{e}-3$ & $3.387 \mathrm{e}-4$ & $8.467 \mathrm{e}-5$ & $2.117 \mathrm{e}-5$ & $5.292 \mathrm{e}-6$ & $1.323 \mathrm{e}-6$ \\
\hline & 2nd order & $1.628 \mathrm{e}-3$ & $4.075 \mathrm{e}-4$ & $1.019 \mathrm{e}-4$ & $2.548 \mathrm{e}-5$ & $6.369 \mathrm{e}-6$ & $1.592 \mathrm{e}-6$ \\
$\Gamma_{x y}$ & 4th order & $7.011 \mathrm{e}-4$ & $1.748 \mathrm{e}-4$ & $4.368 \mathrm{e}-5$ & $1.092 \mathrm{e}-5$ & $2.730 \mathrm{e}-6$ & $6.823 \mathrm{e}-7$ \\
& 6th order & $6.985 \mathrm{e}-4$ & $1.747 \mathrm{e}-4$ & $4.367 \mathrm{e}-5$ & $1.092 \mathrm{e}-5$ & $2.730 \mathrm{e}-6$ & $6.823 \mathrm{e}-7$ \\
\hline
\end{tabular}

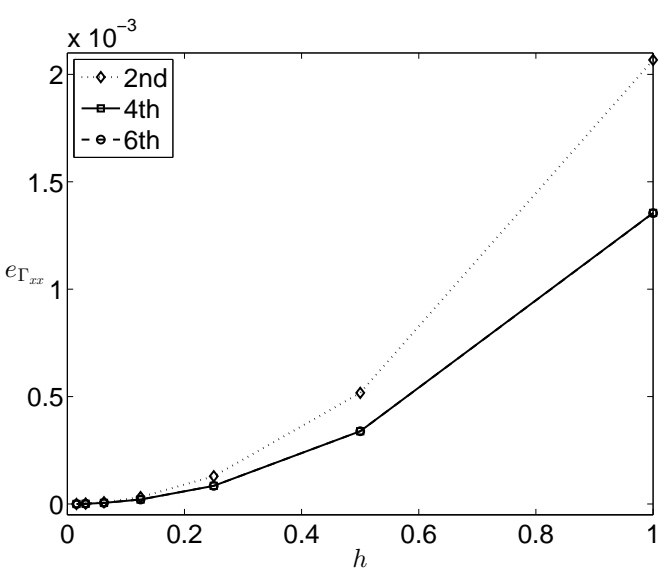

(a)

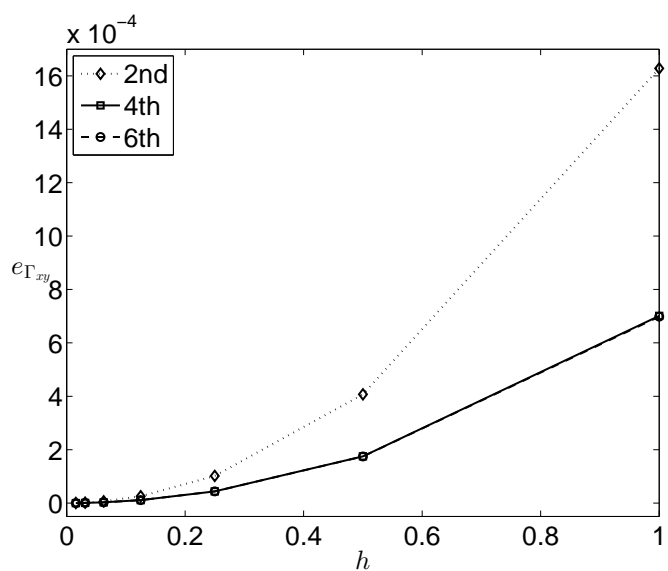

(b)

FIgURE 4. Relative error of (a) $\Gamma_{x x}$ and (b) $\Gamma_{x y}$ with high order schemes.

3.2.3. Theta $(\Theta)$. Theta, $\Theta$, is defined as the rate of change in option prices depending on the passage of time. Theta is also called time decay of the portfolio, whose numerical discretization is given as 


$$
\begin{aligned}
(\Theta)_{i j}^{n} & :=\left(\frac{\partial u}{\partial \tau}\right)_{i j}^{n}=\frac{u_{i j}^{n+1}-u_{i j}^{n-1}}{2 \Delta \tau}+O\left((\Delta \tau)^{2}\right) \\
& =\frac{u_{i j}^{n-2}-8 u_{i j}^{n-1}+8 u_{i j}^{n+1}-u_{i j}^{n+2}}{12 \Delta \tau}+O\left((\Delta \tau)^{4}\right) \\
& =\frac{u_{i j}^{n+3}-9 u_{i j}^{n+2}+45 u_{i j}^{n+1}-45 u_{i j}^{n-1}+9 u_{i j}^{n-2}-u_{i j}^{n-3}}{60 \Delta \tau}+O\left((\Delta \tau)^{6}\right) .
\end{aligned}
$$

\begin{tabular}{|c|c|c|c|c|c|}
\hline error $\Delta \tau$ & 0.1 & 0.02 & 0.004 & 0.0008 & 0.00016 \\
\hline 2nd & $3.157 e-3$ & $1.242 \mathrm{e}-4$ & 4.963 & $1.985 \mathrm{e}-7$ & $7.945 \mathrm{e}-9$ \\
\hline 4 th order & $2.437 \mathrm{e}-4$ & $3.458 \mathrm{e}-7$ & $5.505 \mathrm{e}-10$ & $3.628 \mathrm{e}-13$ & $8.373 \mathrm{e}-12$ \\
\hline 6th order & $7.033 e-5$ & $2.959 \mathrm{e}-9$ & $4.265 \mathrm{e}-13$ & $2.421 \mathrm{e}-13$ & $1.278 \mathrm{e}-11$ \\
\hline
\end{tabular}

TABLE 5. elative error of $\Theta$ with respect to $\Delta \tau$ when $(\Theta)_{a}=$ $-2.309767981220711 \mathrm{e}-1$.

In Table 5, we can obtain that the relative error with the 4th order scheme becomes larger than the 6th order scheme's one. Also, we can see that the relative error with 4th and 6th order schemes converges rapidly as $\Delta \tau$ decreases as shown in Fig. 5. From this result, we can notice that the 4th order scheme is accurate enough to calculate the Theta and there can be arisen an error if too small $\Delta \tau$ is used. Enough smaller $\Delta \tau$ used will reduce the numerical error in general, while much smaller $\Delta \tau$ used will make the relative error increase, due to the round-off error. Thus, $\Delta \tau$ should be chosen with care.

3.3. Searching algorithm for optimal increments. Now, we propose a new algorithm for evaluating the Rho $(\rho)$ and the Vega $(\nu)$. To calculate the Rho and the Vega, we need to choose appropriate sizes of increments $\Delta r$ and $\Delta \sigma$. Too large increments can cause a large discretization error and too small increments also generate round up errors. Therefore, it is important to carefully choose the optimal increment values. To determine whether the used parameter is optimal or not, we use the normalized step difference error $E_{m}$ and it is defined as

$$
E_{m}=\left|\frac{\phi_{m}-\phi_{m-1}}{\phi_{m-1}}\right| \text {, }
$$

where $m=2,3,4, \cdots$.

Next, we draw the new algorithm for evaluating Rho and Vega as following steps:

Step 1: Set $s=10, \Delta r=r_{0} / s, t o l=1 \mathrm{e}-8$, and $m=2$. And we choose a large value $E_{1}=100$ to hold the $\left|E_{2}-E_{1}\right|>$ tol.

Step 2: Run the simulations with $r=r_{0}+\Delta r$ and $r=r_{0}-\Delta r$ and denote their solutions as $u\left(r_{0}+\Delta r_{0}\right)$ and $u\left(r_{0}-\Delta r_{0}\right)$, respectively. 


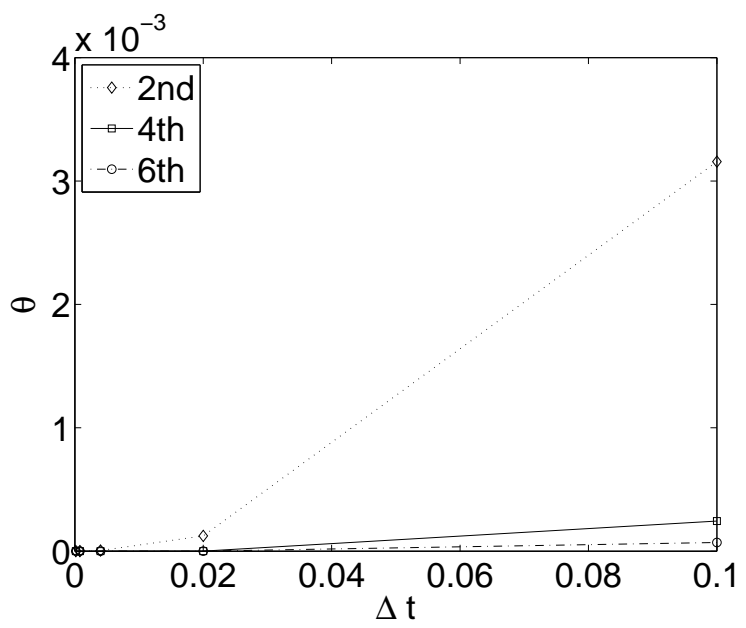

FIGURE 5. Relative error of $\Theta$ with 2nd, 4th, and 6th order difference schemes.

Step 3: Compute $E_{m}$. If $E_{m}>t o l$ and $\left|E_{m}-E_{m-1}\right|>t o l$, then $\Delta r=\Delta r / s, m=$ $m+1$, and return to step 2. Else stop the simulation.

Step 4: If $E_{m}>E_{m-1}$, then stop the simulation and set $m=m-1$.

It is optional to do Step 3 and 4. Instead of those steps, we can just set the number of iteration of simulations. To calculate Rho and Vega in next subsections, we omit the optional steps and simulate with $10^{-n} r, n=1,2,3,4,5,6$. Now, we consider tests with our proposed method.

3.3.1. Rho $(\rho)$. Rho, $\rho$, is defined as the rate of change in option prices when the risk-free interest rate's changing. If the risk-free interest rate increases, then call option price also increases. By applying a center difference, Rho is written as follow:

$$
(\rho)_{i j}^{n}:=\left(\frac{\partial u}{\partial r}\right)_{i j}^{n}=\frac{u_{i j}^{n}(r+\Delta r)-u_{i j}^{n}(r-\Delta r)}{2 \Delta r}+O\left((\Delta r)^{2}\right) .
$$

In Table 6, it is shown that the normalized step difference error for $\rho$ at underlying asset $(100,100)$ and $T=0.5$ against the risk-free interest rate's step size. As the step size is decreasing, the normalized error is also decreasing until $\Delta r=10^{-4} r$. If the step size is less than $10^{-5} r$, however, the normalized error becomes increasing. Here, we compute the $\rho$ by using a set of different $r_{0} / s^{m}$, i.e., $r_{0} / s, r_{0} / s^{2}, \ldots$ If the normalized error or the change of two normalized errors is smaller than a given tolerance, i.e., tol for an iteration $m$, we choose the step as $\Delta r=r_{0} / s^{m}$.

3.3.2. Vega $(\nu)$. Vega, $\nu$, is defined as the rate of change in option prices for the volatility of the underlying assets. Since some option values can be sensitive to changes in volatility, vega has an important role to monitor in volatile markets, especially. 
TABLE 6. Normalized step difference error for $\rho$ (Underlying Asset) $=$ $(100,100), T=0.5)$.

\begin{tabular}{|c|c|c|c|c|c|c|}
\hline$\Delta r$ & $10^{-1} r$ & $10^{-2} r$ & $10^{-3} r$ & $10^{-4} r$ & $10^{-5} r$ & $10^{-6} r$ \\
\hline$E$ & & $1.134 \mathrm{e}-5$ & $1.139 \mathrm{e}-7$ & $8.189 \mathrm{e}-9$ & $1.263 \mathrm{e}-8$ & $4.544 \mathrm{e}-7$ \\
\hline
\end{tabular}

$$
\begin{aligned}
& \left(\nu_{x}\right)_{i j}^{n}:=\left(\frac{\partial u}{\partial \sigma_{1}}\right)_{i j}^{n}=\frac{u_{i j}^{n}\left(\sigma_{1}+\Delta \sigma_{1}\right)-u_{i j}^{n}\left(\sigma_{1}-\Delta \sigma_{1}\right)}{2 \Delta \sigma_{1}}+O\left(\left(\Delta \sigma_{1}\right)^{2}\right), \\
& \left(\nu_{y}\right)_{i j}^{n}:=\left(\frac{\partial u}{\partial \sigma_{2}}\right)_{i j}^{n}=\frac{u_{i j}^{n}\left(\sigma_{2}+\Delta \sigma_{2}\right)-u_{i j}^{n}\left(\sigma_{2}-\Delta \sigma_{2}\right)}{2 \Delta \sigma_{2}}+O\left(\left(\Delta \sigma_{2}\right)^{2}\right) .
\end{aligned}
$$

Tables 7 show the normalized error with difference $\Delta \nu$. As explained above, it shows similar result which the error becomes decreasing unless the step size $\Delta \nu$ is not too small. This result represents that finding suitable step size is vital for an effective estimation.

TABLE 7. Normalized step difference error for $\nu$ (Underlying Asset $=$ $(100,100), T=0.5)$.

\begin{tabular}{ccccccc}
\hline$\Delta \sigma_{1}$ & $10^{-1} \sigma_{1}$ & $10^{-2} \sigma_{1}$ & $10^{-3} \sigma_{1}$ & $10^{-4} \sigma_{1}$ & $10^{-5} \sigma_{1}$ & $10^{-6} \sigma_{1}$ \\
\hline$E$ & & $3.180 \mathrm{e}-3$ & $3.163 \mathrm{e}-5$ & $3.164 \mathrm{e}-7$ & $1.111 \mathrm{e}-8$ & $6.317 \mathrm{e}-8$ \\
\hline
\end{tabular}

\section{Conclusion}

We presented a computational algorithm for calculating option prices and the Greeks of a two-asset cash-or-nothing option. The value of the option was modeled by using the BS partial differential equation and the governing equation was discretized by the finite difference method. Using the OS method, we could solve the discrete equation efficiently. Since a cashor-nothing option has closed-form solutions for the option price and the Greeks, the exact and numerical values were compared. We described further details on the process and numerical results demonstrating the accuracy and robustness of our proposed algorithm. From the results, we investigated that there is the proper high order scheme to evaluate the Greeks and found an optimal guideline to choose a suitable increment. The proposed algorithm is general, therefore, it can be applied to other options. As future research, we will investigate barrier and equitylinked securities (ELS) options using the proposed scheme. 


\section{APPENDIX}

The exact formula for the option price given in $[11,12]$ is as follows:

$$
u(x, y, \tau)=K e^{-r \tau} M\left(\alpha, \beta ; \rho_{x y}\right),
$$

where $\alpha=\frac{\ln \left(x / K_{1}\right)+\left(r-\sigma_{1}^{2} / 2\right) \tau}{\sigma_{1} \sqrt{\tau}}, \beta=\frac{\ln \left(y / K_{2}\right)+\left(r-\sigma_{2}^{2} / 2\right) \tau}{\sigma_{2} \sqrt{\tau}}$, and $M\left(\alpha, \beta ; \rho_{x y}\right)$ is a standardized cumulative normal function with the correlation $\rho_{x y}$

$$
M\left(\alpha, \beta ; \rho_{x y}\right)=\frac{1}{2 \pi \sqrt{1-\rho_{x y}^{2}}} \int_{-\infty}^{\alpha} \int_{-\infty}^{\beta} e^{-\frac{\xi^{2}-2 \rho_{x y} \xi \eta+\eta^{2}}{2\left(1-\rho_{x y}^{2}\right)}} d \eta d \xi .
$$

\section{응응응응응응응응응응 Option value 응응응응응응응응응응}

clear; tau=0.5; K1=100;K2=100; K=10; $r=0.03 ; \mathrm{sig} 1=0.3 ; \mathrm{sig} 2=0.3 ; \mathrm{rho}=0.5 ; \mathrm{x}=100 ; \mathrm{y}=100$ alpha $=(\log (x / K 1)+(r-\operatorname{sig1} \wedge 2 / 2) * \operatorname{tau}) /(\operatorname{sig} 1 * \operatorname{sqrt}(\operatorname{tau}))$;

beta $=(\log (y / K 2)+(r-\operatorname{sig} 2 \wedge 2 / 2) * \operatorname{tau}) /(\operatorname{sig} 2 * \operatorname{sqrt}($ tau $))$;

$\mathrm{u}=\mathrm{K} \star \exp (-r * t a u) \star \operatorname{mvncdf}([\mathrm{alpha}$ beta], [0 0], [1 rho; rho 1])

Now, we find the explicit Greek formulas by differentiating Eq. (5.1).

$$
\begin{aligned}
& \Delta_{x}=\frac{\partial u}{\partial x}=\frac{K e^{-r \tau}}{2 \pi x \sigma_{1} \sqrt{\tau} \sqrt{1-\rho_{x y}^{2}}} \int_{-\infty}^{\beta} e^{-\frac{\alpha^{2}-2 \rho_{x y} \alpha \eta+\eta^{2}}{2\left(1-\rho_{x y}^{2}\right)}} d \eta, \\
& \Delta_{y}=\frac{\partial u}{\partial y}=\frac{K e^{-r \tau}}{2 \pi y \sigma_{2} \sqrt{\tau} \sqrt{1-\rho_{x y}^{2}}} \int_{-\infty}^{\alpha} e^{-\frac{\xi^{2}-2 \rho_{x y} \xi \beta+\beta^{2}}{2\left(1-\rho_{x y}^{2}\right)}} d \xi .
\end{aligned}
$$

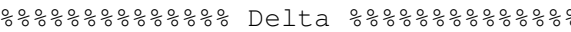

clear; $\operatorname{tau}=0.5 ; \mathrm{K} 1=100 ; \mathrm{K} 2=100 ; \mathrm{K}=10 ; \mathrm{r}=0.03 ; \mathrm{sig} 1=0.3 ; \mathrm{sig} 2=0.3 ; \mathrm{rho}=0.5 ; \mathrm{x}=100 ; \mathrm{y}=100$;

alpha $=(\log (x / K 1)+(r-\operatorname{sig1} 2 / 2) * \operatorname{tau}) /(\operatorname{sig} 1 * \operatorname{sqrt}(\operatorname{tau})) ;$

beta $=\left(\log (y / K 2)+\left(r-\operatorname{sig} 2^{\wedge} 2 / 2\right) * \operatorname{tau}\right) /(\operatorname{sig} 2 * \operatorname{sqrt}($ tau $))$;

delta $1=K * \exp \left(-r * \operatorname{tau}-0.5 * a l p h a^{\wedge} 2\right) /(\operatorname{sqrt}(2 * \mathrm{pi}) * x * \operatorname{sig} 1 * \operatorname{sqrt}($ tau $)) \ldots$ $\star$ normcdf (beta, rho*alpha, sqrt (1-rho^2))

delta $2=K \star \exp (-r * \operatorname{tau}-0.5 *$ beta^2) / (sqrt $(2 * \mathrm{pi}) * y * \operatorname{sig} 2 * \operatorname{sqrt}(\operatorname{tau})) \quad \ldots$ $\star \operatorname{normcdf}(\mathrm{alpha}$, rho*beta, sqrt (1-rho^2))

$$
\begin{aligned}
& \Gamma_{x x}=\frac{\partial^{2} u}{\partial x^{2}}=\frac{K e^{-r \tau}}{2 \pi x^{2} \sigma_{1} \sqrt{\tau} \sqrt{1-\rho_{x y}^{2}}} \int_{-\infty}^{\beta}\left(\frac{\rho_{x y} \eta-\alpha}{\sigma_{1} \sqrt{\tau}\left(1-\rho_{x y}^{2}\right)}-1\right) e^{-\frac{\alpha^{2}-2 \rho_{x y} \alpha \eta+\eta^{2}}{2\left(1-\rho_{x y}^{2}\right)}} d \eta, \\
& \Gamma_{y y}=\frac{\partial^{2} u}{\partial y^{2}}=\frac{K e^{-r \tau}}{2 \pi y^{2} \sigma_{2} \sqrt{\tau} \sqrt{1-\rho_{x y}^{2}}} \int_{-\infty}^{\alpha}\left(\frac{\rho_{x y} \xi-\beta}{\sigma_{2} \sqrt{\tau}\left(1-\rho_{x y}^{2}\right)}-1\right) e^{-\frac{\xi^{2}-2 \rho_{x y} \xi \beta+\beta^{2}}{2\left(1-\rho_{x y}^{2}\right)}} d \xi, \\
& \Gamma_{x y}=\frac{\partial^{2} u}{\partial x \partial y}=\frac{K e^{-r \tau}}{2 \pi x y \sigma_{1} \sigma_{2} \tau \sqrt{1-\rho_{x y}^{2}}} e^{-\frac{\beta^{2}-2 \rho_{x y} \beta \alpha+\alpha^{2}}{2\left(1-\rho_{x y}^{2}\right)}} .
\end{aligned}
$$




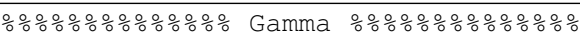

clear; $\operatorname{tau}=0.5 ; \mathrm{K} 1=100 ; \mathrm{K} 2=100 ; \mathrm{K}=10 ; \mathrm{r}=0.03 ; \mathrm{sig} 1=0.3 ; \mathrm{sig} 2=0.3 ; \mathrm{rho}=0.5 ; \mathrm{x}=100 ; \mathrm{y}=100$; alpha $=(\log (\mathrm{x} / \mathrm{K} 1)+(\mathrm{r}-\operatorname{sig} 1 \wedge 2 / 2) * \operatorname{tau}) /(\operatorname{sig} 1 * \operatorname{sqrt}(\operatorname{tau})) ;$

beta $=\left(\log (\mathrm{y} / \mathrm{K} 2)+\left(\mathrm{r}-\operatorname{sig} 2^{\wedge} 2 / 2\right) * \operatorname{tau}\right) /(\operatorname{sig} 2 * \operatorname{sqrt}(\operatorname{tau}))$;

gamma $1=K * \exp \left(-r * \operatorname{tau}-0.5 * a l p h a^{\wedge} 2\right) /\left(\operatorname{sqrt}(2 * \mathrm{pi}) * \mathrm{x}^{\wedge} 2 * \operatorname{sig} 1 \wedge 2 *\right.$ tau $) \ldots$

* $\left(-r h o * \exp \left(-0.5 *(\right.\right.$ beta $\left.-r h o * a l p h a) \wedge 2 /\left(1-r h 0^{\wedge} 2\right)\right) / \operatorname{sqrt}\left(2 * \mathrm{pi} *\left(1-r h 0^{\wedge} 2\right)\right) \quad \ldots$

$+(-$ alpha-sigl 1 sqrt (tau) $) *$ normcdf (beta, rho*alpha, sqrt (1-rho^2)) )

gamma $2=K * \exp (-r * \operatorname{tau}-0.5 *$ beta^ 2$) /\left(\operatorname{sqrt}(2 * \mathrm{pi}) * \mathrm{y}^{\wedge} 2 * \operatorname{sig} 2^{\wedge} 2 * \operatorname{tau}\right) \ldots$

$*\left(-r h o * \exp \left(-0.5 *(a l p h a-r h o * \text { beta })^{\wedge} 2 /\left(1-r h 0^{\wedge} 2\right)\right) / \operatorname{sqrt}\left(2 * \mathrm{pi} *\left(1-r h 0^{\wedge} 2\right)\right) \quad \ldots\right.$

$+(-$ beta-sig $2 * \operatorname{sqrt}($ tau $)) * \operatorname{normcdf}\left(\right.$ alpha, rho*beta, $\left.\left.\operatorname{sqrt}\left(1-r h 0^{\wedge} 2\right)\right)\right)$

gamma $3=\mathrm{K} * \exp (-\mathrm{r} * \mathrm{tau}) /\left(2 * \mathrm{p} i * \mathrm{x} * \mathrm{y} * \operatorname{sig} 1 * \operatorname{sig} 2 * \operatorname{tau} * \operatorname{sgrt}\left(1-r h 0^{\wedge} 2\right)\right) \quad \ldots$ $\star \exp (-0.5 *($ beta`2 $-2 * r h o *$ beta*alpha+alpha^2) /(1-rho^2))

$$
\begin{aligned}
\rho=\frac{\partial u}{\partial r}=\frac{K e^{-r \tau}}{2 \pi \sqrt{1-\rho_{x y}^{2}}}\left\{-\tau \int_{-\infty}^{\alpha} \int_{-\infty}^{\beta} e^{-\frac{\xi^{2}-2 \rho_{x y} \xi \eta+\eta^{2}}{2\left(1-\rho_{x y}^{2}\right)}} d \eta d \xi\right. \\
\left.\quad+\frac{\sqrt{\tau}}{\sigma_{1}} \int_{-\infty}^{\beta} e^{-\frac{\alpha^{2}-2 \rho_{x y} \alpha \eta+\eta^{2}}{2\left(1-\rho_{x y}^{2}\right)}} d \eta+\frac{\sqrt{\tau}}{\sigma_{2}} \int_{-\infty}^{\alpha} e^{-\frac{\xi^{2}-2 \rho_{x y} \xi \beta+\beta^{2}}{2\left(1-\rho_{x y}^{2}\right)}} d \xi\right\} .
\end{aligned}
$$

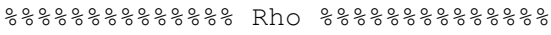

clear; $\operatorname{tau}=0.5 ; \mathrm{K} 1=100 ; \mathrm{K} 2=100 ; \mathrm{K}=10 ; \mathrm{r}=0.03 ; \operatorname{sig} 1=0.3 ; \mathrm{sig} 2=0.3 ; \mathrm{rho}=0.5 ; \mathrm{x}=100 ; \mathrm{y}=100$; alpha $=\left(\log (\mathrm{x} / \mathrm{K} 1)+\left(\mathrm{r}-\operatorname{sig} 1^{\wedge} 2 / 2\right) * \operatorname{tau}\right) /(\operatorname{sig} 1 * \operatorname{sgrt}(\operatorname{tau})) ;$ beta $=\left(\log (\mathrm{y} / \mathrm{K} 2)+\left(\mathrm{r}-\operatorname{sig} 2^{\wedge} 2 / 2\right) * \operatorname{tau}\right) /(\operatorname{sig} 2 * \operatorname{sgrt}(\mathrm{tau}))$;

rrho $=-\operatorname{tau} * \mathrm{~K} * \exp (-r * t a u) * \operatorname{mvncdf}([\mathrm{alpha}$ beta], [0 0], [1 rho; rho 1])...

$+\operatorname{sqrt}($ tau $) * K * \exp \left(-r * \operatorname{tau}-0.5 * a l p h a^{\wedge} 2\right) /(\operatorname{sqrt}(2 * \mathrm{pi}) * \operatorname{sig} 1) \ldots$

$*$ normcdf (beta, rho*alpha, sqrt $\left.\left(1-r h 0^{\wedge} 2\right)\right) \ldots$

$+\operatorname{sqrt}($ tau $) * K * \exp (-r * \operatorname{tau}-0.5 *$ beta^ 2$) /(\operatorname{sqrt}(2 * \mathrm{pi}) * \operatorname{sig} 2) \ldots$ $\star$ normcdf (alpha, rho*beta, sqrt (1-rho^2));

$$
\begin{aligned}
\Theta=\frac{\partial u}{\partial t}=\frac{-K e^{-r \tau}}{2 \pi \sqrt{1-\rho_{x y}^{2}}} & \left\{r \int_{-\infty}^{\alpha} \int_{-\infty}^{\beta} e^{-\frac{\xi^{2}-2 \rho_{x y} \xi \eta+\eta^{2}}{2\left(1-\rho_{x y}^{2}\right)}} d \eta d \xi\right. \\
+ & \frac{\ln \left(x / K_{1}\right)-\left(r-\sigma_{1}^{2} / 2\right) \tau}{2 \sigma_{1} \tau^{3 / 2}} \int_{-\infty}^{\beta} e^{-\frac{\alpha^{2}-2 \rho_{x y} \alpha \eta+\eta^{2}}{2\left(1-\rho_{x y}^{2}\right)}} d \eta \\
& \left.+\frac{\ln \left(y / K_{2}\right)-\left(r-\sigma_{2}^{2} / 2\right) \tau}{2 \sigma_{2} \tau^{3 / 2}} \int_{-\infty}^{\alpha} e^{-\frac{\xi^{2}-2 \rho_{x y} \xi \beta+\beta^{2}}{2\left(1-\rho_{x y}^{2}\right)}} d \xi\right\} .
\end{aligned}
$$

\section{응응응응응응응응응응응응응응 Theta 응응응응응응응응응응응응응}

clear; $\operatorname{tau}=0.5 ; \mathrm{K} 1=100 ; \mathrm{K} 2=100 ; \mathrm{K}=10 ; \mathrm{r}=0.03 ; \mathrm{sig} 1=0.3 ; \mathrm{sig} 2=0.3 ; \mathrm{rho}=0.5 ; \mathrm{x}=100 ; \mathrm{y}=100$; alpha $=(\log (x / K 1)+(r-\operatorname{sig} 1 \wedge 2 / 2) * \operatorname{tau}) /(\operatorname{sig} 1 * \operatorname{sgrt}(\operatorname{tau}))$;

beta $=\left(\log (\mathrm{y} / \mathrm{K} 2)+\left(\mathrm{r}-\operatorname{sig} 2^{\wedge} 2 / 2\right) * \operatorname{tau}\right) /(\operatorname{sig} 2 * \operatorname{sqrt}(\operatorname{tau}))$;

theta $=-r * K * \exp (-r *$ tau $) * \operatorname{mvncdf}([$ alpha beta],$[0$ 0], [1 rho; rho 1]) ...

$-\left(\log (x / K 1)-\left(r-\operatorname{sig} 1^{\wedge} 2 / 2\right) * \operatorname{tau}\right) * K * \exp (-r * \operatorname{tau}-a l p h a \wedge 2 / 2) /(2 * \operatorname{sqrt}(2 * \mathrm{pi}) * \operatorname{sig} 1 \ldots$ $\left.\star \operatorname{tau}^{\wedge}(3 / 2)\right) \star \operatorname{normcdf}\left(\operatorname{beta}\right.$, rho*alpha, $\left.\operatorname{sqrt}\left(1-r h 0^{\wedge} 2\right)\right) \ldots$ 
$-\left(\log (y / K 2)-\left(r-\operatorname{sig} 2^{\wedge} 2 / 2\right) * \operatorname{tau}\right) * K * \exp \left(-r * \operatorname{tau}-\operatorname{beta}{ }^{\wedge} 2 / 2\right) /(2 * \operatorname{sqrt}(2 * \mathrm{pi}) * \operatorname{sig} 2 \ldots$ *tau^(3/2)) *normcdf (alpha, rho*beta, sqrt (1-rho^2))

$$
\begin{aligned}
& \nu_{x}=\frac{\partial u}{\partial \sigma_{1}}=\frac{K e^{-r \tau}}{2 \pi \sqrt{1-\rho_{x y}^{2}}}\left(-\frac{\ln \left(x / K_{1}\right)+\left(r+\sigma_{1}^{2} / 2\right) \tau}{\sigma_{1}^{2} \sqrt{\tau}}\right) \int_{-\infty}^{\beta} e^{-\frac{\alpha^{2}-2 \rho_{x y} \alpha \eta+\eta^{2}}{2\left(1-\rho_{x y}^{2}\right)}} d \eta, \\
& \nu_{y}=\frac{\partial u}{\partial \sigma_{2}}=\frac{K e^{-r \tau}}{2 \pi \sqrt{1-\rho_{x y}^{2}}}\left(-\frac{\ln \left(y / K_{2}\right)+\left(r+\sigma_{2}^{2} / 2\right) \tau}{\sigma_{2}^{2} \sqrt{\tau}}\right) \int_{-\infty}^{\alpha} e^{-\frac{\xi^{2}-2 \rho_{x y} \xi \beta+\beta^{2}}{2\left(1-\rho_{x y}^{2}\right)}} d \xi .
\end{aligned}
$$

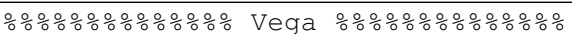

clear; tau=0.5; K1=100; K2=100; K=10; $\mathrm{r}=0.03 ; \mathrm{sig} 1=0.3 ; \mathrm{sig} 2=0.3 ; \mathrm{rho}=0.5 ; \mathrm{x}=100 ; \mathrm{y}=100$;

alpha $=\left(\log (x / K 1)+\left(r-\operatorname{sig1}^{\wedge} 2 / 2\right) * \operatorname{tau}\right) /(\operatorname{sig} 1 * \operatorname{sqrt}(\operatorname{tau})) ;$

beta $=\left(\log (y / K 2)+\left(r-\operatorname{sig} 2^{\wedge} 2 / 2\right) * \operatorname{tau}\right) /(\operatorname{sig} 2 \star \operatorname{sqrt}(\operatorname{tau}))$;

$\operatorname{vega} 1=-\left(\log (x / K 1)+\left(r+\operatorname{sig} 1^{\wedge} 2 / 2\right) * \operatorname{tau}\right) /\left(\operatorname{sig} 1^{\wedge} 2 * \operatorname{sqrt}(\operatorname{tau})\right) * K * \exp (-r * \operatorname{tau}-\mathrm{alpha} 2 / 2) \quad \ldots$ / sqrt $(2 \star \mathrm{pi}) \star$ normcdf (beta, rho*alpha, sqrt (1-rho^2))

vega $2=-\left(\log (y / K 2)+\left(r+\operatorname{sig} 2^{\wedge} 2 / 2\right) * \operatorname{tau}\right) /\left(\operatorname{sig} 2^{\wedge} 2 * \operatorname{sqrt}(\operatorname{tau})\right) * K \star \exp (-r * \operatorname{tau}-$ beta^2/2) $\ldots$ / sqrt $(2 * \mathrm{pi}) *$ normcdf (alpha, rho*beta, sqrt (1-rho^2))

\section{ACKNOWLEDGMENTS}

This work was supported by the National Institute for Mathematical Sciences(NIMS) grant funded by the Korea government(No. A21301). The authors thank the reviewers for the constructive and helpful comments on the revision of this article. The authors would like to thank Chaeyoung Lee and Jeahyun Jo for their valuable assistance in the preparation of this manuscript.

\section{REFERENCES}

[1] M. Chesney, R.J. Elliott, D. Madan, and H. Yang, Diffusion coefficient estimation and asset pricing when risk premia and sensitivities are time varying, Math. Financ. 313 (1993), pp. 85-99.

[2] A.J. McNeil and R. Frey, Estimation of tail-related risk measures for heteroscedastic financial time series: an extreme value approach, J. Empirical Financ. 713 (2000), pp. 271-300.

[3] J. Huang, M.G. Subrahmanyam, and G.G. Yu, Pricing and hedging American options: a recursive investigation method, Rev. Financ. Stud. 913 (1996), pp. 277-300.

[4] P. Wilmott, Paul Wilmott on quantitative finance. Wiley, New York, 2000.

[5] Y. El-Khatib and N. Privault, Computations of Greeks in a market with jumps via the Mulliavin calculus, Financ. Stoch. 813 (2004), pp. 161-179.

[6] M. Namihira and D.A. Kopriva, Computation of the effects of uncertainty in volatility on option pricing and hedging, Int. J. Comput. Math. 1389 (2012), pp. 1281-1302.

[7] F. Black and M. Sholes, The pricing of options and corporate liabilities. J. Polit. Econ. 8113 (1973), pp. 637-59.

[8] D.J. Duffy, Finite difference methods in financial engineering : a partial differential equation approach, John Wiley and Sons, New York, 2006.

[9] S. Ikonen and J. Toivanen, Operator splitting methods for American option pricing, Appl. Math. Lett. 1713 (2004), pp. 809-814. 
[10] D. Jeong and J. Kim, A comparison study of ADI and operator splitting methods on option pricing models, J. Comput. Appl. Math. 24713 (2013), pp. 162-171.

[11] E.G. Haug, The complete guide to option pricing formulas, McGraw-Hill, New York, 1997.

[12] D. Jeong, J. Kim, and I.S. Wee, An accurate and efficient numerical method for black-scholes equations, Commun. Korean Math. Soc. 2413 (2009), pp. 617-628. 